\title{
Technical tip: fixation of extra-articular fractures of distal humerus with modified distal tibial locking plate
}

\author{
Gupta R. ${ }^{1}$, Maheshwari V. ${ }^{2}$, Gour S. ${ }^{3}$, Narendra Kumar ${ }^{4}$, Singh A. ${ }^{5}$ \\ ${ }^{1}$ Dr. Rajul Gupta, Assistant Professor, ${ }^{2}$ Dr. Vaibhav Maheshwari, Assistant Professor, ${ }^{3}$ Dr. Sandeep Gour, Senior \\ Resident, ${ }^{4}$ Dr. Narendra Kumar, Associate Professor; above authors are attached with Department of Orthopaedics, \\ Chirayu Medical College and Hospital, Bhopal (M.P.), ${ }^{5}$ Dr. Avtar Singh, Director, Amandeep Hospital, Amritsar, \\ Punjab, India.
}

Corresponding Author: Dr. Vaibhav Maheshwari, Assistant Professor, Department of Orthopaedics, Chirayu Medical College \& Hospital, Bhopal (M.P.) E-mail:drvaibhavm16@gmail.com

\begin{abstract}
Introduction- Treatment of extra-articular distal humerus fractures is often difficult using conventional plates. Plates having enough screws (three to four) in the distal fragment either impinge on the olecranon fossa, or gain purchase by placing screws in the lateral or medial column of the distal humerus avoiding the olecranon fossa. Objectives- This study was to ascertain the effectiveness of modified distal tibial locking plate for use in distal third shaft humerus fracture. Methods- By using a modified distal tibial locking plate, a six to eight locking head screws can be easily placed in the in the limited length of distal fragment proximal to the olecranon fossa. Fourteen cases treated in such manner were followed up for a minimum of 24 months. Results- Union was achieved in all cases with no loss of reduction or implant failure. No patient complained of hardware complication, functional limitation or infection. Conclusion- Modified distal locking plate can be safely used in the limited space above olecrenon fossa in distal thirds humerus shaft fractures
\end{abstract}

Keywords: Distal humerus; Fracture; Plate fixation; Locking plate.

\section{Introduction}

Fractures of distal part of humerus are difficult to treat, despite recent advances in surgical technique [1]. Functional bracing, though advocated, may not provide adequate stability and acceptable alignment due to the distal extent of these fractures.

Optimal treatment of these injuries is surgical, providing a predictable alignment quicker return to pre injury status [2] Stable fixation and reduced surgical time lead to fewer complications and allow earlier rehabilitation leading to a more predictable result. In the the clinical and functional outcomes using the extraarticular distal humerus plate in the management of extraarticular fractures of distal humerus were studied
[3]. Anatomy of distal humerus is complex, and often the fracture pattern adds o the complexity of situation [4]. During open reduction and plate fixation, achieving purchase of 6 to 8 cortices on distal fragment often causes encroachment of olecranon fossa [5].

To address these problems, authors used a modified medial sided distal tibial locking compression plate (Kanghui, Jiangsu, China) for fixation of distalhumerus shaft fracture. The provision of multiple holes in plate meant for fixation of distal tibial fractures provides multiple screw fixation options in distal humerus improving distal fixation without encroachment on the olecranon fossa.

\section{Material and Methods}

Setting of the study- This study was performed in Chirayu Medical College and hospital, a tertiary level facility, under department of orthopaedics.

Sample size- A total of 14 cases were included in this study. These include 11 cases of acute trauma and three nonunions. All non-unions were operated at least 12 months after trauma.

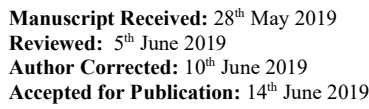


Inclusion Criteria- All consecutive distal third humerus shaft fractures, new cases and established non unions were included in this study.

Exclusion criteria- All fractures with intra-articular extentions, cases with previous hardware placement, Follow up period Average follow up was 27 months (range 24 to 31 months). Radiographic union was documented.

Surgical technique- The following methodology was applied:

Modification of the plate- The distal tibial locking plate of adequate length is selected for modification. The plate was straightened using plate benders in order to achieve a better fir to the relatively flat posterior surface of humerus. By repeated bending, the distal tab was broken off in order to prevent encroachment on the olecranon fossa (Figure 1).

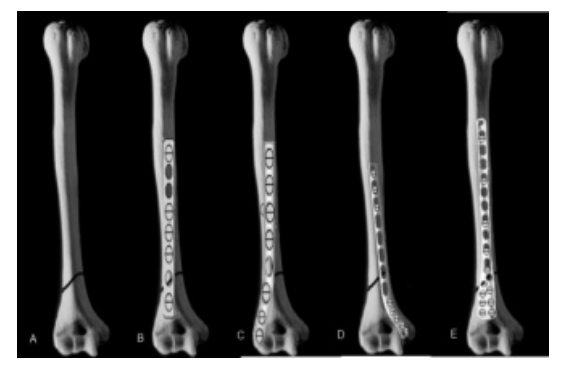

Figure-1: The locking plate for lower end tibia is modified by separating the distal tab from the plate. The plate is then straightened for application over the posterior surface of the distal humerus.

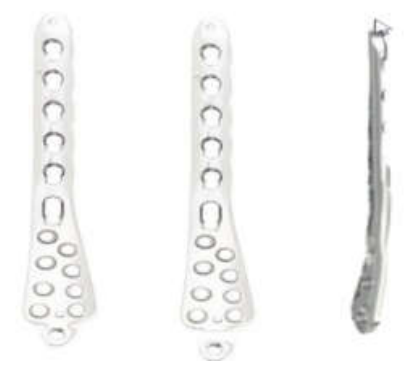

Figure-2: Intra operative photograph showing the plate after fixation of distal humerus shaft fracture. Six locking screws could be placed in distal humerus, providing stable fixation.

Black arrow points to the location of the radial nerve.

Plate application- Posterior triceps splitting approach is used for plate fixation (Figure 2). After identification of the radial nerve, the fracture ends are identified and cleaned. Reduction is then achieved, and if required interfragmentary screws are placed. Plate is now applied. One or two cortical screws are first placed to fix the plate to shaft of humerus. Distal locking $3.5 \mathrm{~mm}$ screws are now placed. It is possible to place a maximum of eight locking screws allowing strong fixation with multiple screws in a relatively small area of the distal fragment proximal to the olecranon fossa (Figure 2). Wound is closed in standard fashion. No immobilization of any kind is given after surgery. On the first post-operative day, gentle, passive mobilization of shoulder, elbow and wrist is initiated. By 3 weeks, active range of motion is achieved. Patient is followed up every 4 weeks. Institutional ethical committee approval was obtained in all cases

\section{Results}

Out of 14 cases in the present study (Table 1), 11 cases were of acute trauma and three non-unions. All non-unions were operated at least 12 months after trauma. Average follow up period was 27 months (range 24 to 31 months). Radiographic confirmation of union was documented by the presence of bridging callus and disappearance of the fracture line. All fractures united. Mean time to union was 11 weeks (range 8 to 16 weeks). Average range of motion was 5 to 121 degrees at 24 months. There were no instances of superficial or deep surgical site infection. There were no complaints of painful hardware. One patient had post-operative radial nerve palsy, and two patients had pre operative radial nerve palsy but all had full recovery at 24 months of follow up. 


\section{Research Article}

Table-1: Table showing indication for surgery, classification and outcome of patients treated by our method.

\begin{tabular}{|c|c|c|c|c|}
\hline $\begin{array}{c}\text { Patient } \\
\text { number }\end{array}$ & Indication for operative treatment & $\begin{array}{c}\text { Fracture } \\
\text { classification }\end{array}$ & $\begin{array}{c}\text { Time to } \\
\text { union(weeks) }\end{array}$ & Complication \\
\hline 1 & Multiple fractures & $12 \mathrm{~A} 1$ & 12 & None \\
\hline 2 & Open fracture & $12 \mathrm{~B} 1$ & 16 & None \\
\hline 3 & Non union & $12 \mathrm{~B} 2$ & 12 & None \\
\hline 4 & Obesity, osteoporosis & $12 \mathrm{~A} 1$ & 16 & None \\
\hline 5 & Open fracture and radial nerve palsy & $12 \mathrm{C} 1$ & 8 & None \\
\hline 6 & Multiple fractures & $12 \mathrm{~B} 3$ & 8 & Post operative \\
\hline 7 & Non union & $12 \mathrm{~A} 2$ & 12 & radial nerve palsy \\
\hline 8 & Multiple fractures, Obesity & $12 \mathrm{~A} 1$ & 8 & None \\
\hline 9 & Open fracture & $12 \mathrm{~B} 2$ & 8 & None \\
\hline 10 & Bilateral humerus fractures & $12 \mathrm{C} 3$ & 12 & None \\
\hline 11 & Floating Elbow & $12 \mathrm{~B} 1$ & 8 & None \\
\hline 12 & Non union & $12 \mathrm{~A} 1$ & 12 & None \\
\hline 13 & Open Fracture, Radial nerve pasly & $12 \mathrm{C} 1$ & 8 & None \\
\hline 14 & Multiple fractures & $12 \mathrm{C} 1$ & 12 & \\
\hline
\end{tabular}

\section{Case Examples}

Case 1 - Acute fracture- A 31 year old sustained a comminuted fracture of distal third of the humeral shaft (AO/OTA type 12C3) in a road traffic accident (Figure 3A). He was operated upon the same day and a modified lower tibial locking plate was used to fix the fracture. Autologous bone graft from iliac crest was added because of comminuted fracture. Union was achieved in 14 weeks (Figure 3B).

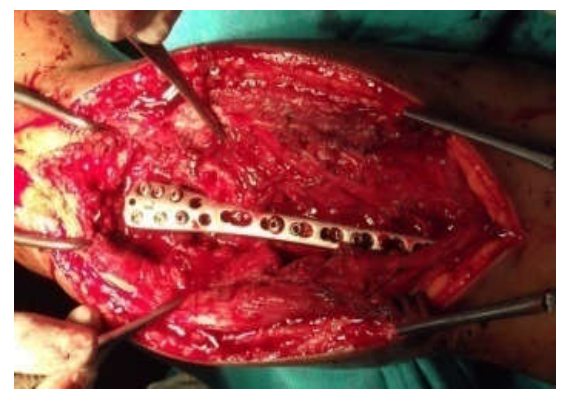

Figure-3a: Preoperative radiographs showing comminuted distal humerus shaft fracture.

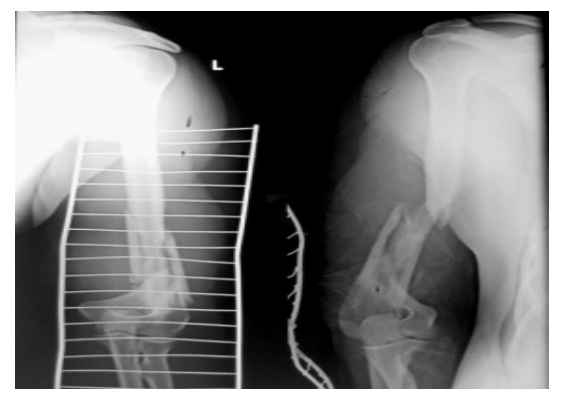

Figure-4a: Non Union of distal humerus shaft. Pre operativeradiopgraphs taken twelve months after injury 


\section{Research Article}

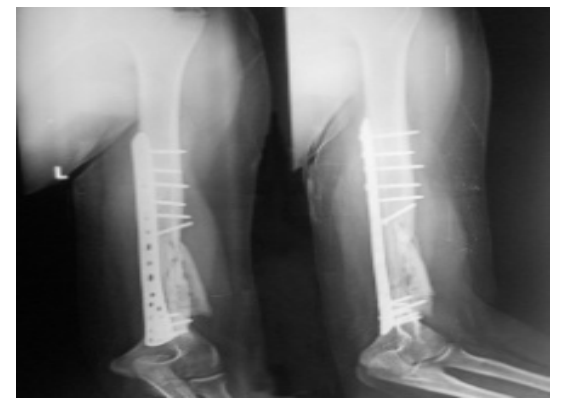

Figure-4b: Post operative radiographs showing fracture union.

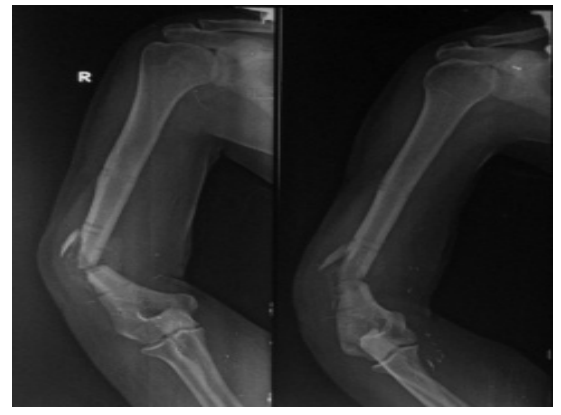

Figure-5A: Fracture of distal third of humeral shaft are often located too close to olecrenon fossa to allow adequate number of screws in the distal fragment with conventional posterior plates.

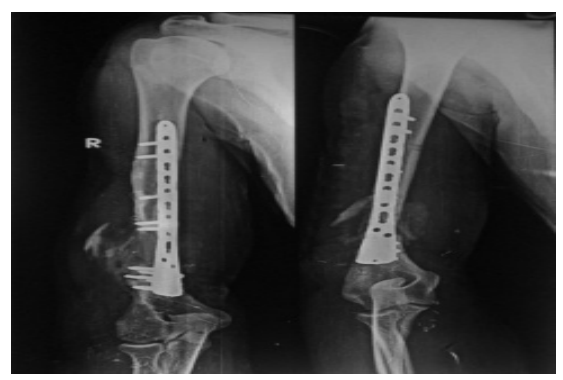

Figure-5B: A dynamic compression plate applied in the centre of posterior surface of humerus never allows placement of adequate number of screws without impinging on the olecrenon fossa.

Case 2-Non Union- A 46 year old male sustained a Gustilo and Anderson grade III C compound fracture of distal humeral shaft (AO/OTA type 12C3) with brachial artery injury. Brachial artery repair was done and fracture was stabilized with an external fixator. External fixator was removed after eight weeks and for 10 more months patient was given an arm brace. Clinically and radiologically, there were no signs of union twelve months after injury (Figure 4A). Open reduction and internal fixation with modified distal tibial locking plate was done. Autologous bone graft from the ipsilateral iliac crest was added to the fracture site. Union was achieved in ten weeks (Figure 4B).

\section{Discussion}

Optimal treatment of distal third of the humeral shaft is challenging [6]. Schatzker and Tile cite availability of a flat posterior surface and the option of double plating as reasons for plating the distal humerus fractures posteriorly [7]. Most authors agree that purchase in six to eight cortices on either side of fracture is optimal in humerus shaft fractures $[8,5]$. Centrally located conventional plates of adequate length when used for posterior fixation of fracture of distal third of the humeral shaft often cause encroachment of olecranon fossa (Figure 5A, 5B) [5]. Several authors have tried to address this problem. Moran advised placing the plate with 5-8 degrees obliquity with respect to long axis of femur and directing the most distal screw proximally. However, obliquity of the plate prevented proximal screw placement required in segmental fractures, comminuted fractures and fractures with proximal extension [9]. To counter this problem, Levy described 


\section{Research Article}

an innovative technique, using a modified lateral head tibial buttress plate with a 22 degree angular offset. This could achieve fixation in the lateral column of distal humerus without impinging on the olecranon fossa and still allow proximal fixation as the plate was axially aligned with the shaft (Figure 5C) [10]. Cutting the plate requires additional instrumentation which normally may not be present in many operating room setups. Scolaro described the use of a pre-contoured distal humerus locking plate for distal humerus extraarticular fractures (Figure 5D) [11]. Also, Jain et al used an extra articula posterolateral locking plate and reported a reoperation rate of $15.4 \%$ [3].

Theirs and other similar techniques technique of using posterolateral locking plate may cause more soft tissue stripping which could potentially decrease the vascularity of distal fragment. These three authors utilized the lateral column of the distal humerus for gaining screw purchase in the distal fragment.

Some authors have used intramedullary nails for distal humerusfixation. The short length of the medullary canal in the distal fragment precludes stable fixation even when locked and can cause non-union or malunion [9]. .In comminuted fractures the fixation provided by intramedullay nails is poor, especially if the size of the diaphyseal canal doesn't fit with the nail, leading to high rates of mal- or non-union.

Distal locking of the nail may weaken the humeral cortex and produce fractures [12]. Biomechanical studies have shown superior bending properties of humeral fractures fixed with a plate and screw system versus intramedullary device [14].

Use of a modified distal tibial locking plate for treatment of extra articular distal humerusmetaphyseal fractures affords good stability by availability of multiple screws in the small area available for fixation (Figure 5E). These screws are locking screws affording rigid fixation. Using the medial or the lateral column for screw fixation as is done the posterolateralmetaphyseal locking plate or as in utilizing both columns also increases the size of incision and soft tissue stripping. The current technique has resulted in a 100 percent union rate, which is comparable or better as compared to other authors.

\section{Conclusion}

This technique provides a method for fixation of distal humerusdiaphyseal fractures with implant readily available in most setups. Modification of the plate is easy, and instruments needed are also commonly available. Solid purchase is possible in the limited length of bone proximal to the olecranon fossa with multiple locking screws. Rapid rehabilitation is thus possible owing to solid fixation.

Since the plate fixation does not involve the medial or lateral columns of the distal humerus, soft tissue stripping is considerably less. This fixation method can also be adopted for comminuted and segmental fractures. This easy surgical technique can be picked up and easily repeated by virtually every orthopaedic surgeon.

\section{What this study adds to existing knowledge?}

This study presents an innovative approach of dealing with diatlhumerus fractures without extensive dissection with great biomechanical stability

\section{Contribution by different authors}

- Dr. Rajul Gupta- performed all the surgeries

- Dr.Vaibhav Maheshwari prepared the manuscript and made the necessary corrections.

- Dr. Sandeep Gaur was involved in the research, patient follow up and post operative care

- Dr. Narendra Kumar was consulted for the late presenting non union cases

- Dr. Avtar Singh is the originator of the idea of using this implant in these fractures

Conflict of interest: None declared.

Funding: Nil, Permission from IRB: Yes

\section{References}

1. U1 Islam S, Glover AW, Waseem M. Challenges and Solutions in Management of Distal Humerus Fractures. Open Orthop J. 2017;11:1292-1307. DOI: 10.2174/1874 325001711011292 . eCollection 2017.

2. Jawa A, McCarty P, Doornberg J, Harris M, Ring D. Extra-articular distal-third diaphyseal fractures of the humerus. A comparison of functional bracing and plate fixation. J Bone Joint Surg Am. 2006 ;88(11):2343-7. DOI:10.2106/JBJS.F.00334

3. Jain D, Goyal GS, Garg R, Mahindra P, Yamin M, Selhi HS. Outcome of anatomic locking plate in extraarticular distal humeral shaft fractures. Indian $\mathrm{J}$ Orthop. 2017; 51(1):86-92. DOI: 10.4103/0019-5413. 197554. 


\section{Research Article}

4. Morrey BF. The elbow and its disorders. Elsevier Health Sciences; 2009.

5. McKee MD. Fractures of the shaft of the humerus. In Rockwood and Green's Fractures in Adults, Bucholz RW, Heckman JD, Court-Brown CM, Editors. 2006, Lippincott Williams \& Wilkins: Philadelphia. p.11171159.

6. Aitken GK, Rorabeck CH. Distal humeral fractures in the adult. Clin Orthop Relat Res. 1986; (207):191-7.

7. Schatzker J, Tile M, Axelrod TS. The rationale of operative fracture care. Berlin: Springer; 2005.

8. Sarmiento A, Waddell JP, Latta LL. Diaphyseal humeral fractures: treatment options. Instr Course Lect. 2002; 51:257-69.

9. Moran MC. Modified lateral approach to the distal humerus for internal fixation. Clin Orthop Relat Res. 1997; (340):190-7. DOI:10.1097/00003086-19970700000024.
10. Levy JC, Kalandiak SP, Hutson JJ, Zych G. An alternative method of osteosynthesis for distal humeral shaft fractures. J Orthop Trauma. 2005;19(1):43-7.

11. Scolaro JA, Voleti P, Makani A, Namdari S, Mirza A, Mehta S. Surgical fixation of extra-articular distal humerus fractures with a posterolateral plate through a triceps-reflecting technique. J of Should Elbow Surg. 2014; 23(2):251-7. DOI: 10.1016/j.jse.2013.09.020.

12. Radulescu R, Badila A, Nutiu O, Japie I, Terinte S, Radulescu D, Manolescu R. Osteosynthesis in fractures of the distal third of humeral diaphysis. Maedica. 2014; 9 (1):44.

13. Brug E, Winckler S, Klein W. Distal diaphyseal fractures of the humerus. Unfallchirurg.1994; 97:72-74

14. Kharbanda Y, Tanwar YS, Srivastava V, Birla V, Rajput A, Pandit R. Retrospective analysis of extraarticular distal humerus shaft fractures treated with the use of pre-contoured lateral column metaphyseal LCP by triceps-sparing posterolateral approach. 2017;12(1): 1-9. DOI:10.1007/s11751-016-0270-6

\section{How to cite this article?}

Gupta R, Maheshwari V, Gour S, Narendra Kumar, Singh A. Technical tip: fixation of extra-articular fractures of distal humerus with modified distal tibial locking plate. Surgical Update: Int J surg Orthopedics.2019;5(3):132-137. doi:10.17511/ijoso.2019.i03.02. 